\title{
The Function of Piano Accompaniment in Chorus Teaching
}

\author{
Zhihua Zhang \\ College of Teacher Education \\ Qujing Normal University \\ Qujing, Yunnan,China 655011
}

\begin{abstract}
Chorus is an omnibus artistic form, containing pure natural human voice, exquisite harmony, consummate conducting and appropriate instruments. It is different from solo that chorus is a vivid and graceful musical works performance that is performed by a group of people who has similar sound ray and timbre, and it is characterized most for its voice unification. Simple chorus can be conducted through two-part canon singing a round or leading singing; complex chorus can adopt multi-voice mixed chorus on a certain basis, which makes music have abundant expressive force and shock power. Meanwhile, the implied emotion in the music can be clearly expressed by chorus; it also shortens the distance between audiences and resonate them towards the music. As an underscore, piano accompaniment is irreplaceable in chorus. In the application of chorus works, the expressive form of piano accompaniment is mainly harmony foil and theme melody.
\end{abstract}

Keywords-piano accompaniment; chorus teaching; voice; chorus; piano accompaniment

\section{INTRODUCTION}

As a resplendent pearl in music and art history, chorus has gone through thousands of years of development, and it has evolved from the initial monophonic Gregorian chant into multi-part chorus and formed early motet and Organum chorus from. Until 15th and 17th century, chorus from its basic formation gradually turned into various accompaniments when performing. In China, chorus accompaniment does not have a long history, but many classics were created and a lot of practice and teaching experience are conducted. Therefore, in chorus teaching, teachers should guide students to grasp harmony, timbre and strength of chorus through piano accompaniment, which can promote performers and audiences to resonate in hearts, inspire performers' abundant emotions, enhance students' expressive force in chorus, enrich music tonality and render the atmosphere.

\section{VAlue ANALYSis OF PIANO ACCOMPANIMENT}

\section{A. Embodying Imagination Freedom of Music Creation}

In order to ensure that the created music meets the composer's inner expressive requirements, piano accompanist should apply to their theoretical knowledge and practical experience in judgment and evaluation. To complete this process, accompanists' imagination freedom of music creation is needed, and they will not be too trapped in a certain yoke to escape. Only when accompanists possess imagination freedom of music creation can their musical works have more powerful artistic appeal. In this way, their works can gradually be accepted and spread. Apart from accompanists' musical works, appropriate tonality should also be selected. In the process of selecting appropriate tonality, accompanists also should have imagination freedom of creation. Only when the tonality is blended into musical works can accompanists and tweedle cooperate better, singer's inner emotions be stimulated and musical images be produced.

\section{B. Embodying Spiritual Freedom of Music Freedom}

Accompaniment competence means that the accompanist does not rely on music score, and depends on individual performing techniques and musical knowledge to accompany music or songs. It is also a high requirement for singer because it presents the accompanist's competence to master different types of music. It also requires the accompanist to flexibly do harmonic vocabulary and change tonality. Then the whole music piece can be appreciated from all perspectives by audiences.

\section{Wakening Audiences'Audition}

In the performance of whole music piece, in order to render the musical atmosphere to a certain degree, piano accompanist needs to reflect the music's purpose, background and atmosphere by the melody of piano. In the whole process of performing, the performer's mastering on rhyme and strength of instrument will stimulate audiences' emotions. Through the motion of music melody, the audiences blend themselves into the music performance by visual appeal, and to ensure that audiences' different emotions are aroused.

\section{THE FUNCTION OF PIANO ACCOMPANIMENT IN CHORUS TEACHING}

\section{A. Chorus and Piano Depend on Each Other and Unify as An Organic Whole}

1) Features of human voice: As a tool to express emotions in chorus, human voice has its own advantages. It can direct and clearly convey the implied emotions, presented music form and revealed social phenomenon. Its most striking character is that when a song is sung, the lyrics can be the 
medium to make the audiences directly hear voices; then the implied feelings can be demonstrated. This feeling may be the expression of patriotism, good will for happy life or admiration for national heroes.

2) Features of chorus: Chorus is a music form of collective performing. The gamut it presents is the summation of all participants' gamut. Meanwhile, in the process of chorus, there are often exquisite conduction and instrument accompaniment. Chorus has these features: abundant timbres, broad gamut, highly unified, multi-level of sound and strong expressive force. It is a music performing from that is widespread, high degree of participation and enough imagery. No matter what kind of historical background, artistic style or musical form, it can be conveyed by chorus.

3) Feature of piano accompaniment: People say that piano is the "King of Instruments". In the eternal realm of music, pianos are adopted everywhere. No matter in solo accompaniment of pop music, ortho-spectrum accompaniment of vocal music, symphony tutti of orchestral music or chord accompaniment of chorus music, piano can always occupy a position in music and art circle by its unique timbre, broad volume and alteration of beat. Piano accompaniment can change with the real situation. It can not only present gentle sound stream, graceful melody and subtle prospect, but also broad and brilliant atmosphere, vigorous tonality and splendid scenes. That is one of the reasons why there are the most music forms related to piano. Therefore, those who are studying music and want to study music well should practice piano as much as possible, which will lay a solid foundation for music creation in the future.

\section{B. Chorus Cooperates with Piano to Reveal the Artistic Charm}

The development of chorus art urgently requires a broader space; the advantages of unceasing improvement of piano accompaniment can adapt to expansion of manifestation field. In addition, piano has its unique charm and artistic expressive force, the performer can accomplish multi-music performance on his/her own. Therefore, in post-classicists, adding accompaniment to chorus came into being. Adding piano accompaniment to chorus can enrich its form of manifestation. When chorus cooperates with piano, broader performance space and abundant expressive force can be exerted, and the utmost charm of art can be revealed.

\section{Chorus Cooperates with Piano to Strengthen the Theme}

In the platform of chorus teaching, the participants are like brilliant pearls; the accompaniment is the gold thread. The scatted pearl can only be gathered by the gold thread; then it can become a priceless treasure. However, the thread just has supplementary functions. The student singes is the focus. Piano is to supplement, stimulate and coordinate students when chorus breath, strength or high pitch makes mistake. What's more, in students' chorus training and practical performance, piano accompaniment plays a role of linkage and engagement. For example, Mongolian composer Yong Rub published Praise of Genghis Khan of Four Seasons. In his work, he chocked all audiences by unique Mongolian khoomei form; then he renders the atmosphere by piano's pillar chord; after that, mixed voice four-parts cooperate with each other. Soprano solo is the extension of prolonged sound, and alto chants to master the melody of voice part. With the assistance of rhythm voice part of tenor and bass to reflect the brilliant atmosphere of the epic. Therefore, in chorus teaching, piano accompaniment techniques should be fully utilized to guide students to master the emotion, voice accuracy, interlude and coda. To one another's linkage, different emotions are produced by engagement with the passage of time to build the work's imaginary due to the performer's rich emotions.

The piano has a strong artistic expressive force. No matter solo performance or chorus accompaniment, it can always render the atmosphere, reveal the creating background and intensively express the composer's emotional consciousness by its beautiful timbre, changeable harmony and broad gamut. Just like the presentation of most works, the introduction part consists of arpeggio, tremolo and broken chord, and each of them is played alternatively; the main part of the music applies to pillar from, rhythmicity and decomposable chord alternation; sub-melody performance polyphony has many contrasts; the theme of the work presents chorus and attaches attention to it. Therefore, in chorus teaching, students' learning depth of piano should be strengthened. They should not only practice more on chorus basic skills and techniques, but techniques of piano accompaniment. After knowing the knowledge of piano accompaniment, they can apply it to chorus teaching performance, to know what and why. In this way, although in actual performance making mistake in timbre, high pitch or beat, they can potentially go back to the norm with the accompaniment of piano.

\section{To Comply with the Aesthetic Treatment of Chorus Works}

The aesthetic treatment of chorus teaching means conductor designs the performance treatment according to the composer's requirements on the basis of knowing and mastering the work. Generally, it contains the following aspects: First, it is the emotion keynotes, i.e., the basic emotion and its alteration of the whole music piece. Second, it is speed and force, which is arranged mainly based on specific works. Third, it is the planning of performance, which is designed by the conductor based on mode, tonality, harmony and polyphony. The last one is the processing of prelude, interlude and coda. It should be noticed that the processing must have stable rhythm, appropriate volume, high spirit and distinctive images. As soon as the accompaniment comes out, emotion of the chorus and audiences should be stimulated to give full play to the rendering and contrast effect of music. Definitely, performance here should be distinguished from piano solo. Solo represents the composer's relatively integrated music conception, and he/she can boldly highlight his/her performance individuality according to the work. Then, the performer him/herself is the "conductor" and "protagonist". However, the piano accompaniment of chorus is not the individual's piano solo; it must make respective adjustment according to the acoustics of chorus and conducting art. After accepting an accompaniment assignment, an excellent piano accompanist will pay attention to esthetic treatment of the 
work with the chorus conductor. In the process of accompaniment, the accompanist must give overall consideration to chorus voice part and accompaniment voice part, analyze its speed, force, rhythm, breath point, climax, difficulty and theme processing. Meanwhile, he/she should make special marks on different aesthetic treatment; then to explore the proper timbre and volume of the chorus. Only in this way can accompanist and conductor have good interaction and cooperation.

\section{Measures to Strengthen the Function of Piano ACCOMPANIMENT IN CHORUS TEACHING}

\section{A. Change Some Teaching Philosophy}

The key of piano accompaniment is the word "accompaniment". Being different from piano performance teaching, the teaching of piano accompaniment also cultivate students' ability of visual play, listening and distinguishing, flexibility, and so on besides teaching piano theoretic knowledge and playing skills. However, some college teachers cannot exactly understand the purpose of piano accompaniment teaching and stick to the traditional teaching philosophy. They train piano accompaniment students through traditional teaching mode, value students' understanding and mastery of piano skills but neglect the cultivation of students' various ability, leading to their superb performance skills but lower accompaniment level. Hence, teachers must change traditional teaching philosophy and the attitudes of laying less importance on piano accompaniment. They also shall correctly evaluate and understand the teaching task and nature of piano accompaniment, put piano accompaniment teaching to the right position, clarify the cultivation direction and aim, set up the goal of training talents and strengthen the training of students' orchestration ability. Thus make students become real piano accompaniment talents that really are needed by the society.

\section{B. Stimulate Learning Interest}

Interest is the best teacher, which is an everlasting truth. Therefore, teachers shall stimulate students' learning interest so as to inspire their positivity of willing participation and innovation. Make students autonomously engage in all learning activities and master the initiative of learning. Only doing this can students truly engage in learning activities and gain the chance for developing and addressing problems, and then achieve the improvement in ability. Hence, teachers must lay emphasis on the stimulation of students' learning interest, try to reduce their learning pressure and arouse their learning enthusiasm so as to make them learning positively and initiatively. In the teaching process, teachers can explain music background to stimulate students' interest. In chorus teaching, most practice songs are strangers to students. In order to stimulate their curiosity, teachers can introduce songs' background in details and make them fully understand the creation intention of the composer so as to arouse their learning interest; besides, teachers can stimulate students' interest by inventing and practicing. In teaching process, teachers can list some examples of inventing and practicing to cultivate their aesthetics and finally achieve the goal of improving their learning interest. When learning interest is owned, the follow-up study will be easy.

\section{Strengthen the Construction of College Faculty}

The teachers' level of a college directly impacts the teaching results of all subjects, and chorus course is not an exception. However, at present, some colleges do not lay enough importance on piano accompaniment in chorus course and is short of piano accompaniment teachers. The piano accompaniment teachers always held concurrently by teachers of piano course or composition theory. Although these teachers have strong professional knowledge and skills, they are not suitable for assuming the task of piano accompaniment teaching for their certain defects. Thus, colleges shall strengthen the construction of faculty to cultivate and absorb a group of professional piano accompaniment teachers. On one hand, colleges shall enhance the training for present piano accompaniment teachers. Since the piano accompaniment teachers are teachers of other relevant courses, to make them satisfy the requirements of piano accompaniment teaching, colleges shall strengthen the training of their relevant knowledge and skills. By various in-jobs training and studying, colleges shall help them solve problems and enhance their quality and ability of all aspects to make them be qualified for professional piano accompaniment teachers. On the other hand, colleges shall absorb a group of professional piano accompaniment talents. Conditional colleges shall take absorbing professional piano accompaniment teachers as the key method. Recruit some talents with good professional knowledge, and strong ability of business, practice and theory to participate in the piano accompaniment teaching of colleges and universities. In this way, owning professional piano accompaniment teachers can not only address the problems of part-time teachers not playing all ability to engage in relevant teaching activities for their heavy workload, but also perfect piano accompaniment teaching to make it glow the new vigor.

\section{CONCLUSION}

Beyond all doubt, piano accompaniment plays an irreplaceable role in chorus teaching. It teaches students to keep up with the pace of music accompaniment in chorus and master the knowledge of piano accompaniment while feeling the works' moods brought by piano accompaniment and expressing the inner emotion. Chorus to piano accompaniment is the icing on the cake. While piano accompaniment to chorus teaching is a tiger with wings added. Therefore, in chorus teaching, only perfectly combining piano accompaniment with choir can upgrade music works to a more perfect art realm.

\section{REFERENCES}

[1] Yang Xiaobo. The Study and Application of Piano Accompaniment [J] Time and Space in Music. 2016(03): 25.

[2] Wan Jiale. An Analysis of Piano Accompaniment in Chinese OperaTaking Liberation to Szechwan Aria as Example [J]. Jiaoxiang-Journal of Xi'an Conservatory of Music. 2015(04): 103.

[3] Sun Danqing. Regional Culture and Music Creation-Piano, Accompaniment in Red Music from the Perspective of Gansu Culture [J]. Modern Music. 2016(07): 28. 
[4] Xiao Lulu. The Role of Piano Accompaniment in the Singing of Sichuan Folk Songs - Take When the Flos Sophorae Blossom as Example [J]. Home of Drama. 2016(06): 65-66.

[5] Mei Qian. On the Art Direction of Piano Accompaniment in the Teaching of Vocal Music [J]. Northern Music. 2016(02): 57. 